macrocephaly, a white retina (lipid retinalis), and hepatosplenomegaly, may be amenable to treatment with a low fat diet that corrects the hyperchylomicronemia.

\title{
MEGALENCEPHALIC CYSTIC LEUKOENCEPHALOPATHY
}

A 41 year-old Japanese male diagnosed with megalencephalic leukoencephalopathy (MLC) with subcortical cysts (van der Knaap disease), presenting at 1 year of age with macrocephaly, slowly progressing after 5 years, seizures beginning at 11 years, completely bed ridden at 18 years, and with long survival, is reported from Tokyo Metropolitan Higashiyamato Medical Center for the Severely Disabled, Japan. His motor function had severely deteriorated and his cognitive function was at a 2 year level. MRI revealed marked cerebral atrophy, ventricular enlargement, and large cysts in frontoparietal and anterior temporal areas. A homozygous missense mutation was detected in the MLCl gene. (Saijo H, Nakayama H, Ezoe T et al. A case of megalencephalic leukoencephalopathy with subcortical cysts (van der Knaap disease): molecular genetic study. Brain Dev August 2003;25:362-366). (Respond: Dr Harumi Saijo, Tokyo Metroplitan Medical Center, 3-44-10 Sakuragaoka, Higashiyamato, Tokyo 207-0022, Japan).

COMMENT. Van der Knaap and colleagues described an infantile onset leukoencephalopathy with swelling and a discrepantly mild clinical course in 8 children in 1995. Mutations of MLC1 gene were identified as a cause of the leukoencephalopathy with subcortical cysts in 2001 (Leegwater et al). The changes in size of basal ganglia and diffuse white matter abnormalities that characterize Canavan and Alexander diseases are not evident in MLC.

\section{ACUTE NECROTIZING ENCEPHALOPATHY}

A 14-month-old girl who presented with sudden onset of unreponsiveness following a fever for 2 days developed decerebrate posturing within 9 hours after admission to Children's Memorial Hospital, Chicago, IL. She had no response to deep pain, her reflexes were exaggerated, and plantar responses were extensor. EEG showed slowing but no epileptiform discharges. B!ood counts and chemistries were ncrmal, except for elevated transaminases, with an aspartate aminotransferase level of $190 \mathrm{IU} / \mathrm{L}$ (normal, 22-59 IU/L). CSF analysis was normal. Initial head CT scan was normal, but 10 hours later, a second CT showed new bilateral thalamic hypodensities. MRI with MR angiography and venography, FLAIR imaging, and apparent diffusion coefficient (ADC) mapping confirmed thalamic and periventricular white matter involvement. Infectious, vascular, metabolic, and other etiologies were excluded. When discharged two weeks later to a rehabilitation facility with a diagnosis of acute necrotizing encephalopathy of childhood (ANEC), the child was blind, she responded only to noxious stimuli, and had diffuse spasticity. (Bassuk AG, Burrowes DM, McRae W. Acute necrotizing encephalopathy of childhood with radiographic progression over 10 hours. Neurology 13 May 2003;60:1552-1553). (Reprints: Dr Alexander G Bassuk, Children's Memorial Hospital, Division of Neurology, Box 51, 2300 Children's Plaza, Chicago, IL 60614). 
COMMENT. Rare in the United States, acute necrotizng encephalopathy (ANE) is reported principally in Japan. The above case in Chicago, extensively investigated by CT and MRI imaging, demonstrates the rapid evolution of thalamic involvement in ANE. Thirteen consecutive children treated and 28 cases of ANE seen at various institutions in Japan are reviewed by Mizuguchi $M$ et al (J Neurol Neurosurg Psychiatry May 1995;58:555-561; see Ped Neur Briefs July 1995). Onset is preceded by upper respiratory infection treated with antipyretics (aspirin in only 2 cases), and impaired consciousness, convulsions, and vomiting develop rapidly within 1 to 3 days. Hematemesis and diarrhea are common, and liver enlargement without jaundice is reported in all patients of this series. Decerebrate posturing occurs with coma, and the mortality is $28 \%$. In survivors, slow recovery begins after 10 days, and spasticity, mental retardation, and seizures are common sequelae. Laboratory findings reveal liver dysfunction, uremia, and hypoproteinemia. Liver histology is nonspecific and unlike Reye's syndrome. CSF protein is increased. CT and MRI show symmetric, multifocal areas of necrosis in the thalami, white matter, brainstem, and cerebellum. The etiology is undetermined, but recent viral infection with influenza, coxackie, and Rotavirus is detected in $20 \%$.

The differential diagnosis, in addition to the acute toxic encephalopathy of Reye's syndrome, includes Wernicke's and Leigh's encephalopathies, carbon monoxide poisoning, ADEM, and acute hemorrhagic leukoencephalitis. An infectious or toxic environmental factor appears most likely. (see Progress in Pediatric Neurology III, PNB Publishers, 1997;pp493-494 for abstract and commentary on ANE).

\section{BEHAVIOR DISORDERS}

\section{MATERNAL SMOKING AND CHILDHOOD HYPERACTIVITY}

A longitudinal, prospective, birth cohort design was used in an investigation of the association between maternal smoking during pregnancy and hyperactivity in 8-year-old children followed at the University Hospital of Oulu, Finland. Teachers assessed behavior by the Children's Behavior Questionnaire (Rutter B2), using a total score of 9 or more to define hyperactivity. At age 8 follow-up, $9.5 \%$ of children were identified as hyperactive. Boys $(14.2 \%, \mathrm{n}=617)$ were more often hyperactive than girls $(4.6 \%, \mathrm{n}=191)$. Smoking during pregnancy was more common among mothers of hyperactive children $(39.7 \%$, $\mathrm{n}=318)$ than of nonhyperactive children $(26.9 \%, \mathrm{n}=2,052)$. Maternal smoking was associated with hyperactivity in a positive dose-response relationship, especially in children of young mothers with low social standing. Single-parent families had the highest proportion of affected children. After adjustment for sex, family structure, socioeconomic status, maternal age, and maternal alcohol use, the odds ratio for a positive association was $1.30 ; 1.08-1.58$ ). (Kotimaa AJ, Moilanen I, Taanila A et al. Maternal smoking and hyperactivity in 8-year-old children. J Am Acad Child Adolesc Psychiatry July 2003;42:826-833). (Reprints: Mr Kotimaa, University Hospital of Oulu, Clinic of Child Psychiatry, PL 26, 90029 OYS, Finland).

COMMENT. Maternal smoking is a potential risk for abnormal brain development and subsequent diagnosis of behavioral disorders. Discontinuing use of nicotine during pregnancy should lessen the incidence of hyperactive behavior in young children. 